\title{
ANALYSIS OF SUSPENSION ELEMENT OF CAR BODY ON THE EXAMPLE SILENTBLOCK
}

\author{
Jan Ziobro' \\ 1 Technical Institute, Jan Grodek State Vocational Academy in Sanok, Mickiewicza 21, 38-500 Sanok, Poland, \\ e-mail: jziobro@pwsz-sanok.edu.pl
}

Received: 2015.10.16

Accepted: 2015.11.14

Published: 2015.12.04

\begin{abstract}
The article presents a still important aspect of the construction and operation of the vehicle. The most loaded part of the suspension of a vehicle has been discussed, for example, rubber-metal bushing (silentblock). This component directly affects the safety and comfort of drive. It also presents the main varieties of construction and signs of usage of those elements. It has comprised of properties of the rubber and polyurethane bushings. Mechanical calculation of silentblock model has also been presented. 3D numerical analysis was carried out on the basis of the model by using two types of rubber bushings with different hardness. The results of simulations carried out in the system MSC.MARC has been shown. On these basis, there were selected and given numerous conclusions for utilitarian character.
\end{abstract}

Keywords: silentblock, rubber-metal bushing, rubber, FEM simulations.

\section{INTRODUCTION}

The parts of the system car chassis fasteners are important and responsible components. One of the most important elements of this system are silent blocks. Usually it is an assembly of two cylindrical metal bushings which are separated by an elastomeric element. Rubber and polyurethanes are most commonly used as the elastomeric material. Table 1 shows the comparison of characteristic properties of the elements which perform the role of absorbing bushing made from rubber and polyurethane.

In the automotive industry there are other determinations than silent block, such as: an elastic connector, elastic anti-vibration bushing, suspension arm bushing assembly [1, 2]. The main tasks of silentblocks include: fixing the body to the chassis, vibrations damping, shocks and impacts transmitted through the wheels from pavement on the chassis and steering system. An example of such an element has been shown in Figure 1.

In industrial practice three manufacturing processes of such elements are used: a) a vulcanized rubber bushing placed between the metal bushings,

b) a vulcanized rubber bushing with an internal metal bushing,

c) a rubber connection without metal screening.

The first solution is now a priority from attention to the smallest damage and assembly errors that many occur. The second solution is a compromise between price, time and assembly precision. The third solution is one of the simplest and cheapest solutions. Unfavorable characteristic is its high sensitivity to an improper assembly method. The consequence of this is the lack of repeatable mechanical properties and a shortened life span, and more frequent need to be replaced.

Among the typical symptoms of the bushing suspension wear are the appearances of:

- growing louder knock from the area of the chassis,

- characteristic jerks when starting and braking,

- rocking body,

- changes in wheel geometry,

- continuous change in the track, 
Table 1. The comparison of the properties of silentblocks

\begin{tabular}{|l|l|}
\hline \multicolumn{1}{|c|}{ Rubber bushing } & \multicolumn{1}{|c|}{ Polyurethane bushing } \\
\hline Better damping properties. & Worse cushioning properties. \\
Long reaction time, & Fast response time, \\
Lower precision of driving conditions of the vehicle & Greater precision of driving the vehicle. \\
Reduction of perceived noise and vibration inside the vehicle, & Increased hardness and stiffness, \\
Improving ride comfort, & Long service life, \\
Small durability, & Possible cracking chassis and body components. \\
The ability to quick wear, & Quick reaction, \\
Slow wear at the first signs of wear. & Higher resistance to dynamic loads, \\
Used mostly in passenger cars. & Avalanche wear after the first signs of wear \\
& Used mostly in off-road vehicles, racing, heavily loaded, etc. \\
\hline
\end{tabular}

- friction wheel during steering wheel arch elements,

- rapid, uneven tread wear in the tires.

In order to ensure traffic safety and a proper car driving, it is absolutely necessary to rebush suspensions, if in the process of it diagnosis had signs of wear. To ensure proper parameters during operation, it is recommended to replace these elements in pairs on both sides. From the driver it requires a constant monitoring of the state that may show signs of wear. It is unacceptable to continue an exploitation of a vehicle with diagnosed wear of these components. The later the operator of the vehicle chooses on the exchange, the more expensive this becomes [3-6].

Bushings smooth and long cylindrical surfaces illustrated in Figure 1 may be used for rigid suspension, or working with a higher loads. A special feature of construction presented in Figure $1 \mathrm{~b}$ is their use for light vehicles, due to a short middle surface. The role of universal use in passenger cars is fulfilled by of silentblocks, which are mapped in Figure 1c-f.

Variations presented in Figure 1g, h, are based on the use of hard rubber. The shock-absorbing properties in the vertical plane are achieved by using appropriate shapes in the bushings. The mapping provided in Figure 1 is a typical sielentblock, in which two bushing made from polyurethane are used. There are also meets from bushings polyurethane solutions without metal interior bushings. In such cases, they have an increased hardness.

\section{EXPERIMENTAL PROCEDURES}

The object of the research is silentblock, which geometrical form and computational mod- el is mapped in Figure 2. In the numerical analysis by using the program MSC.MARC computational procedures were applied: Newton-Rapson, Cauchy, large displacements. The calculation is based on two-parameter mathematical model of the rubber material Mooney-Rivlin. The phase of the angular displacements modeling was carried out using RBE2 node object. Calculations were carried out using two material models of the bushings of modules: G1 $=16000 \mathrm{MPa}$ (Table 2a, c), G2 = $10000 \mathrm{MPa}$ (Table 2b, d-f) [8-11].

\section{RESULTS}

Comparing the results of numerical calculations of silent block for turning about the axis $\mathrm{X}$, which is in the plane Y0Z, as shown in Table 2a, $b$, it can be concluded that in the material of lower hardness less stress values were obtained. There is one interesting case, the situation in which the system was loaded in the $\mathrm{X}, \mathrm{Y}$ and angular displacement around the $\mathrm{Y}$ axis, that is, in a plane X0Y (Table 2c, d). In this case, the stress values decreased significantly for a material with a lower hardness. Obtained values of the total displacement (Table 2e) and their mapping allow the system to see significant deformation of the rubber bushing. Analyzing the image of the displacement of parts and its results (Table 2f) it can be concluded that the internal bushing carries considerable total loads.

\section{CONCLUSIONS}

The research that was carried out allows for identification of these observations. The biggest load in the studied system carries on inner bush- 

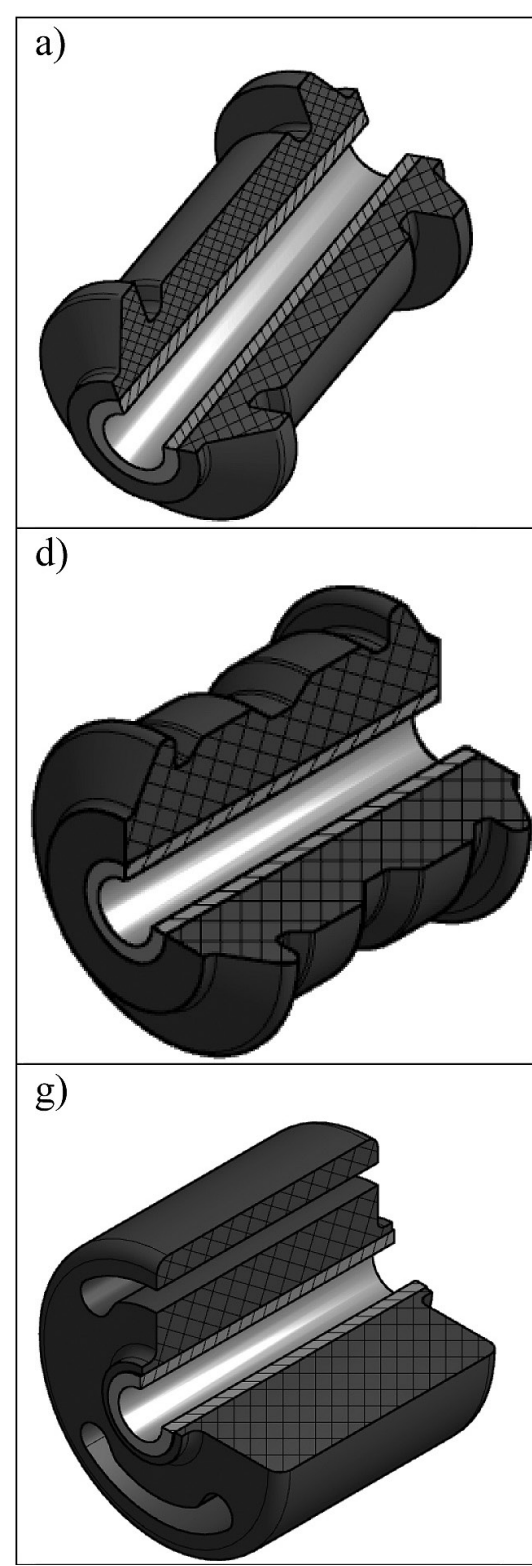

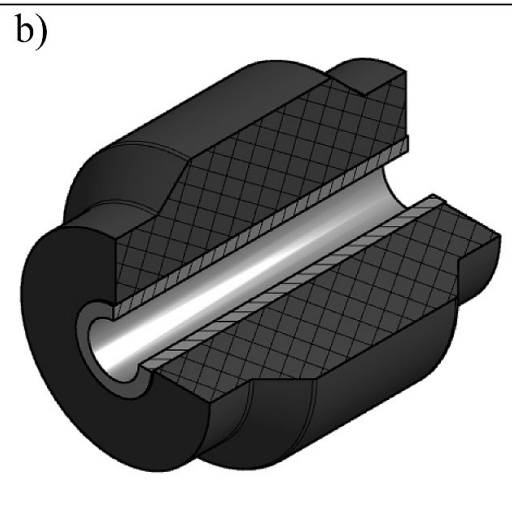

e)

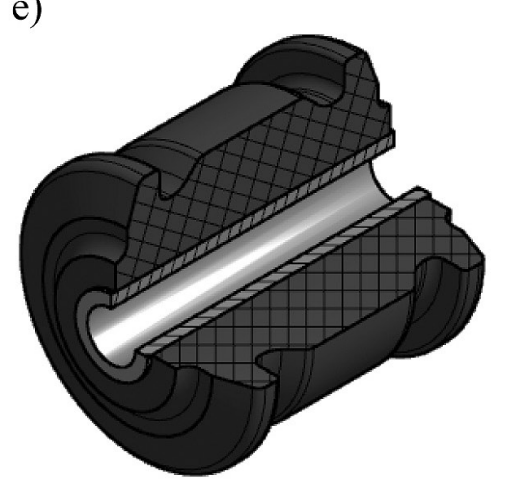

h)

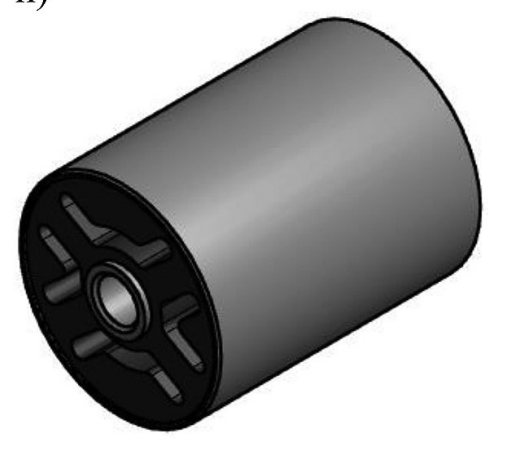

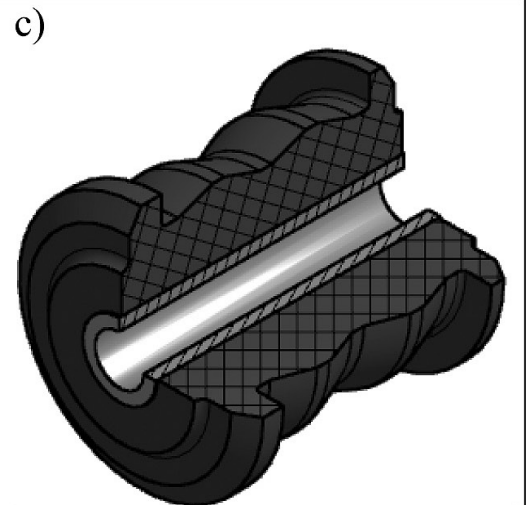

f)

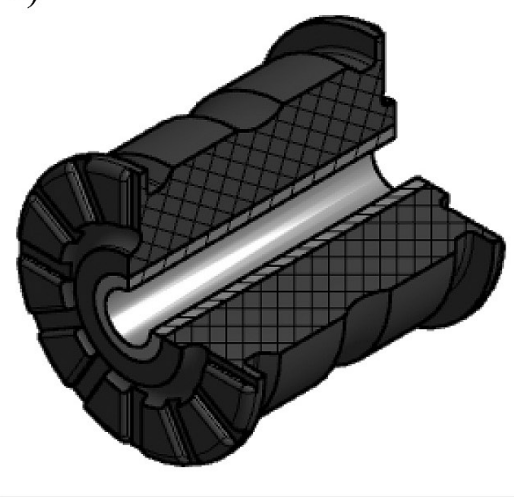

i)

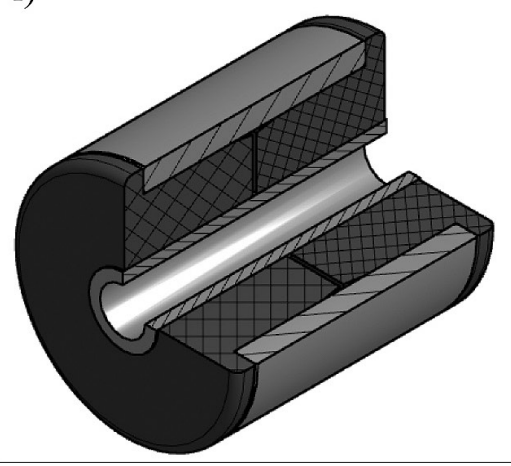

Fig. 1. Mapping of selected types of silentblocks

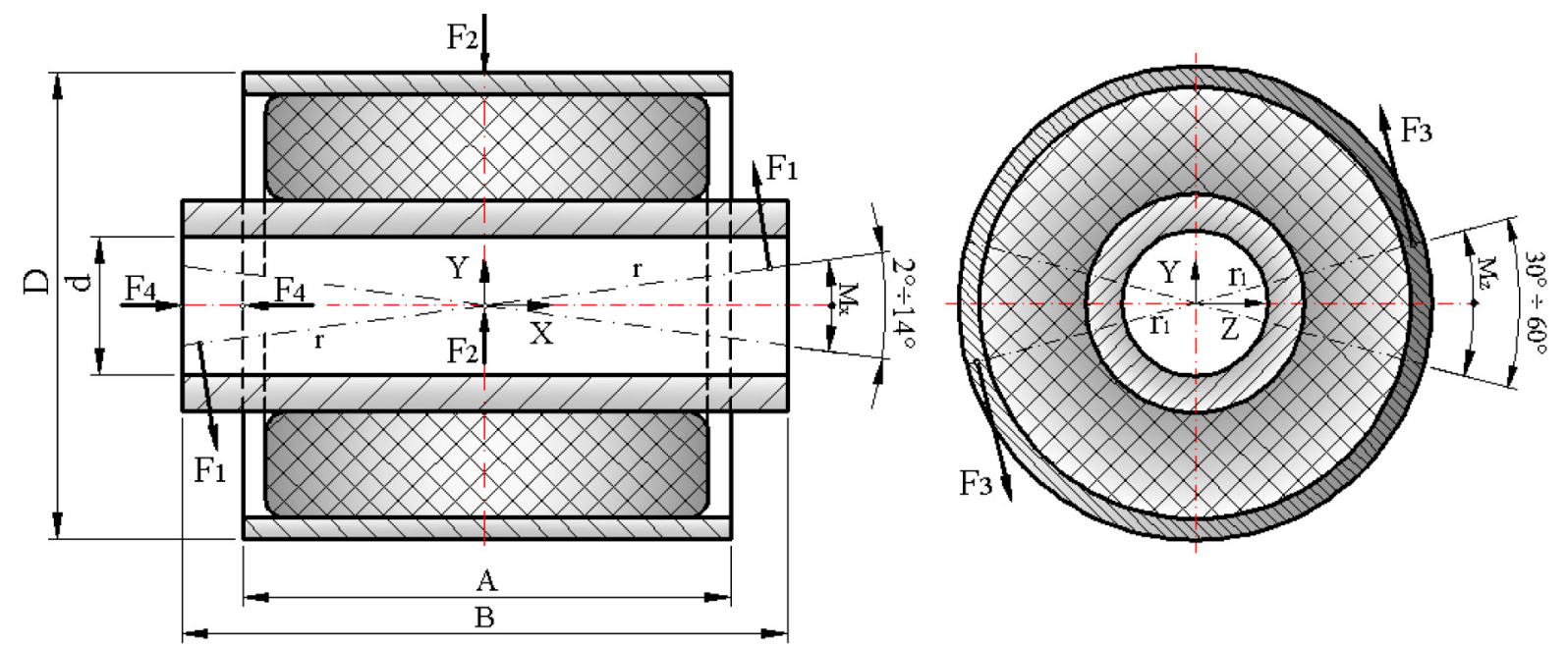

Fig. 2. The silentblock calculation model 
Table 2. Comparison of the results for the two materials

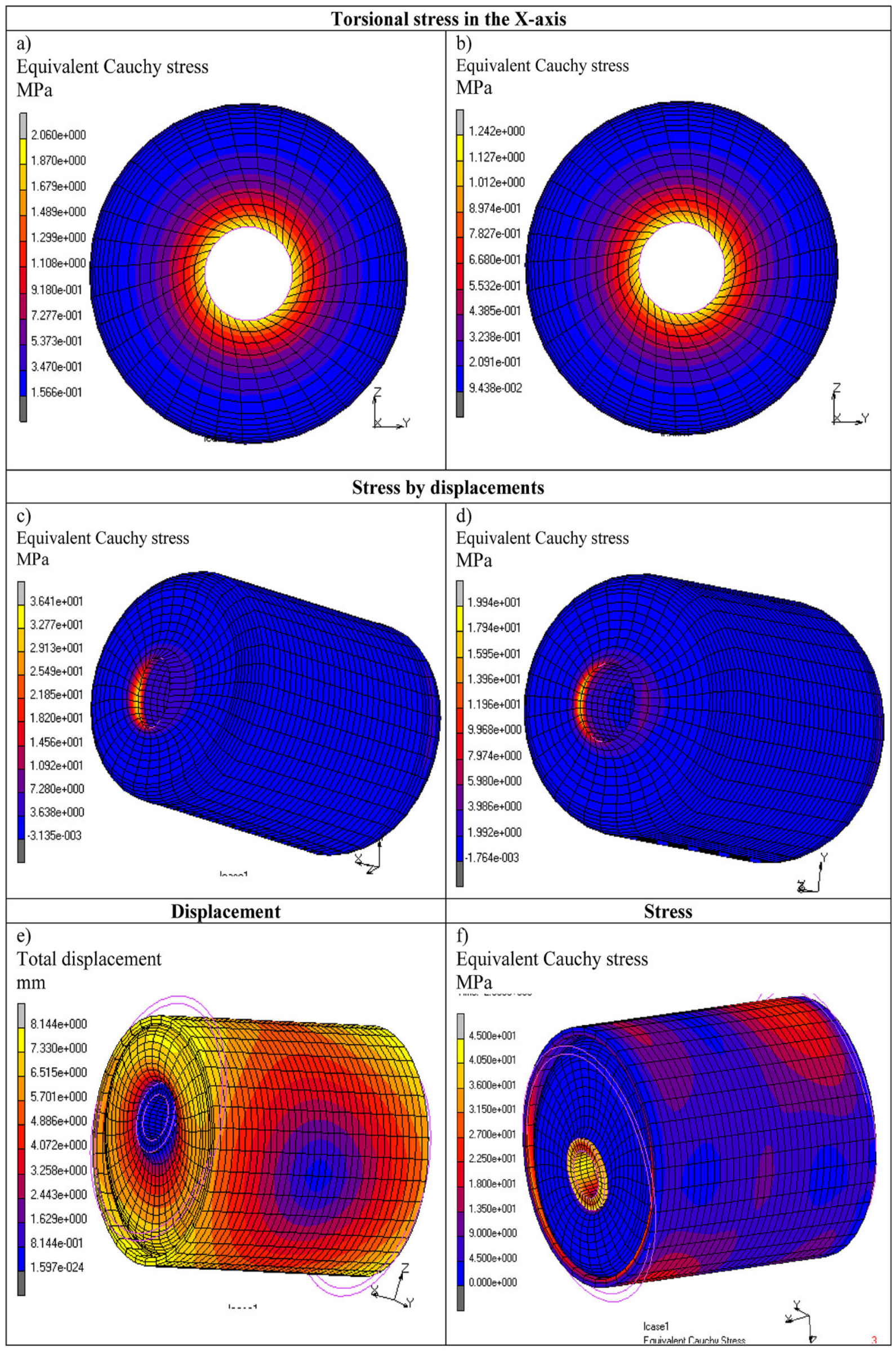


ing. For these reasons, it is recommended to perform it as a part of thick-walled. In addition, it transfers the compressive forces that arise during screwing of silentblocks in body attachment brackets. For the system to be able to work freely it a longer bushing internal is needed. It is unacceptable to use the same length of both bushings. Otherwise, the vehicle operation would become very burdensome, and the vehicle will lose cushioning properties. In such cases, the rubber sleeve may also crack due to on excess of stress. Which in turn significantly would shorten its life period.

In case of application of solid rubber bushings, improving driving comfort, thereby providing adequate damping properties are obtained by using a lower hardness of these elements. A satisfactory compromise between the stability and the damping characteristics can also be obtained by using specially shaped bushing which are made of a harder rubber.

\section{REFERENCES}

1. http://moto-naprawa.pl/wymiana-tulei-wahacza/ \#more-40

2. http://autokult.pl/2876,tuleje-zawieszenia-malyproblem-a-meczy
3. http://mojafirma.infor.pl/moto/eksploatacja-auta/ zawieszenie/255834,Jak-wstepnie-rozpoznac-nadmierne-zuzycie-elementow-zawieszenia.html

4. https://www.ruville.com/fileadmin/user_upload/ redaktion/pdfs/Technikbroschueren/PL/Querlenkerbuchsen_polnisch.pdf

5. Bhowmick A.K. et al. (Ed.): Rubber product and manufacturing technology. Marcel Dekker, New York, USA 1994.

6. Gil-Negrate and Alonso (Eds.): Constitutive models for Rubber VIII. Taylor \& Francis Group, London 2013, 163-196.

7. MSC.Software Corporation Introduction to MSC. Marc and Mentat. MAR101 Course Notes. Help, mar101.pdf.

8. MSC.Software Corporation. Nonlinear finite element analysis of elastomers. Technical Paper. Help, 103_elast_paper.pdf.

9. Ziobro J.: Analiza gumowej osłony przegubu napędowego pojazdu. Zeszyty Naukowe PWSZ Sanok, Nr 9, 2013, 167-175.

10. Ziobro J.: Multiaxial stress and strain analysis of the rubber based on the natural rubber NR. In: International Scientific Conference Pro-Tech-Ma'13. OWPRz, Rzeszów 2013, 258-263.

11. Ziobro J., Marciniec A.: Metodyka projektowania form wtryskowych do elastomerów. OWPRz Rzeszów 2015. 